\title{
Strength comparison of ductile and brittle adhesives under single and repeated impacts
}

\author{
U. Kemiklioglu1*, O. Sayman ${ }^{1}$, T. Batar ${ }^{1}$, I. F. Soykok², T. Akderya ${ }^{1}$ and E. Akan ${ }^{3}$
}

\section{${ }^{*}$ Correspondence:}

ugur.kemiklioglu@gediz.edu.tr

${ }^{1}$ Department

of Mechanical Engineering,

Faculty of Engineering

and Architecture, Gediz

University-Izmir, Menemen,

Izmir, Turkey

Full list of author information

is available at the end of the article

\begin{abstract}
In this study, the failure strengths of adhesively bonded joints were investigated. The glass fiber epoxy composites used as adherends were manufactured by using vacuum assisted resin infusion method (VARIM). The adhesively joint materials were Loctite-9466 and DP-460 as a brittle and ductile material, respectively. Since the strengths of these materials are close to each other under static loading, the applied axial energies were determined using different levels of 5, 10, 15 and 20 Joules. In order to determine the energy characteristics of the experiments, axial impact loadings were applied as both single and repeated three times under the same conditions. The results showed that the failure strengths of these two different adhesives of Loctite-9466 and DP460 changed depending on single and three times repeated axial impact loadings. This paper is intended to give an overview between ductile and brittle adhesives under both single and repeated impacts. In addition, it will help for designers who need information on mechanical properties of ductile and brittle adhesives under single and repeated impacts.
\end{abstract}

Keywords: Glass fibers, Impact behaviour, Damage mechanics, Mechanical testing, Resin transfer moulding (RTM)

\section{Background}

Composites are the materials with lower bulk and higher strength as compared to metals. Besides, composites materials are usually assembled in the forms of mechanical fastened or bonded. Owing to their mechanical, physical and chemical properties such as high strength, weight ratio, high stiffness and less chemical corrosive, composite materials have been greatly used in engineering applications such as aerospace, automotive industry, military, air vehicles, especially for use in aviation and aerospace engineering. Many researcher have been studied different methods to examine the mechanical properties of composite materials and their adhesives to improve the usability of these materials in applications.

Kihara et al. [1] found the shear strength of the adhesive layer under impact test by using experimental method for the case of double-lap joint. Vaidya et al. [2] determined the failure of adhesively bonded joints under effect of transverse impact loading. Yang et al. [3] proposed an analytical solution for obtaining to strain-stress distribution of adhesively composite joints under tension. Sayman et al. [4] investigated an elastic-plastic stress

(c) 2015 Kemiklioglu et al. This article is distributed under the terms of the Creative Commons Attribution 4.0 International License (http://creativecommons.org/licenses/by/4.0/), which permits unrestricted use, distribution, and reproduction in any medium, provided you give appropriate credit to the original author(s) and the source, provide a link to the Creative Commons license, and indicate if changes were made. 
analysis using theoretical methods as well as numerical methods and they showed a good agreement between analytical and numerical methods. In addition to these studies, Kim et al. [5] performed experimental and numerical analysis to find damage modes occurring from out-of-plane impacts. Sayman et al. [6] carried out analytical and numerical elasticplastic stresses in a ductile adhesively bonded single-lap composite joint. Her [7] studied stress analysis in single and double-lap joints using analytical and numerical methods. Keller and Vallee [8] proposed experimental and numerical research for investigating the effects of geometrical parameters on the joint strength. Avilla and Bueno [9] proposed an experimental study on a new design of adhesive bonded joints which is called wavy-lap joint. Aktas and Polat [10] proposed a method to improve the strength of single-lap composite joints by using a pin. As well as, the experiments performed using both numerical and experimental methods many researcher studied only experimental methods using commercial materials. Sayman et al. [11] investigated failure analysis of adhesively bonded composite joints under transverse impact and different temperatures. Loctite-9466 was used as an adhesive material. Temperatures were selected as $-20,23,50$ and $80{ }^{\circ} \mathrm{C}$. The impact energies were applied as 5, 10, 15 and 20 J. Bouchikhi et al. [12] studied the reduction of interfacial stresses when using bonded laminates in strengthening existing structures. They used mixed adhesive joints (MAJs) between the adherents and obtained lower interfacial stresses. Goeij et al. [13] investigated composite adhesive joints under cyclic loading. They compared adhesive joints under static and fatigue failures.

In this study, we carried out a series of experiment on the failure strength at adhesively bonded joints subjected to single and repeated axial impact at different energies of 5, 10, 15 and $20 \mathrm{~J}$. The three times axial impact energies were applied to joints as a repeated impact. Two different adhesives were used with ductile and brittle properties, respectively. These materials are commercially used in composite structures repairements in aerospace, marine and automotive industries.

\section{Methods}

In our study, fiber reinforced polymer (FRP) composite plates were manufactured by using the vacuum infusion method. FRP composite plates composes of glass fibers and resin. We fabricated epoxy glass fiber composites using $\mathrm{E}$ glass fibers and resin via the vacuum infusion method. In order to prepare FRP composite plates, six woven E glass fibers (0.90) with a density of $500 \mathrm{~g} / \mathrm{m}^{2}$ were used with epoxy resin.

After all the bonding surfaces were cleaned with acetone in order to get better adhesion behavior, the glass-fiber epoxy composites were laminated both on a rough and a smooth surfaces. The composite plates were obtained after the rough surfaces were bonded by adhesive materials. The technical dimensions of these bonded composite plate is shown in Fig. 1.

In order to assemble composite materials which require high strengths, we used "Loctite-9466" and "Scotch DP-460" as an adhesive materials to bond the FRP composite plates. All the measurements of FRP composite plates were performed under both axial single and axial repeated impacts and the results were compared to each other. Mechanical properties of the Loctite-9466 and DP-460 are given in Table 1.

As the experimental setup is shown in Fig. 2, the quasi-static test was carried out by using Shimazdzu AG-100 under a loading capacity of $200 \mathrm{kN}$. The test speed was selected as $1 \mathrm{~mm} / \mathrm{min}$. All the experiments were performed in room temperature. 


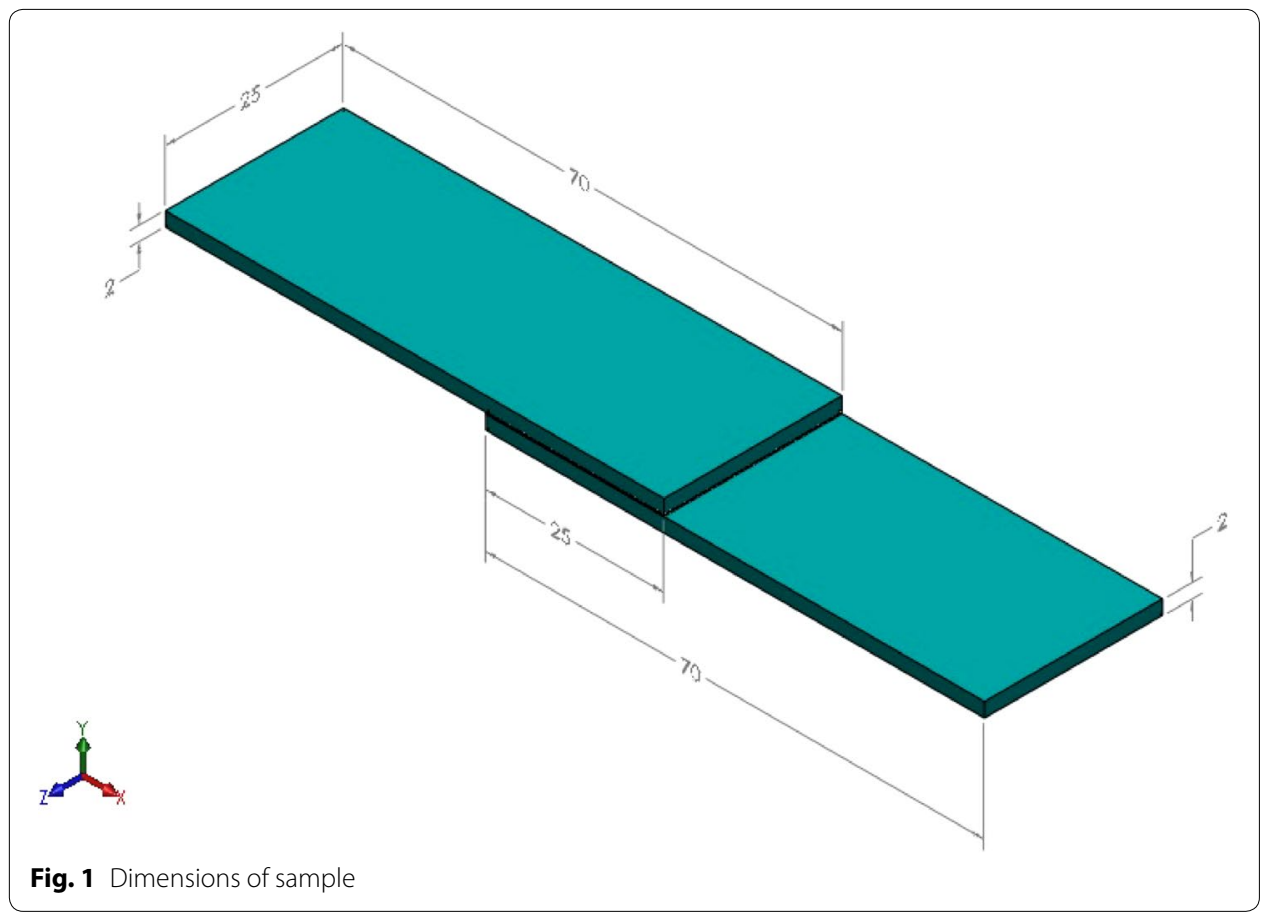

Table 1 Mechanical properties of the Loctite-9466 and DP-460 [14, 15]

\begin{tabular}{llll}
\hline & $\begin{array}{l}\text { Tensile strength } \\
(\mathrm{MPa})\end{array}$ & $\begin{array}{l}\text { Peel strength } \\
(\mathrm{MPa})\end{array}$ & $\begin{array}{l}\text { Service temperature } \\
\text { range }\left({ }^{\circ} \mathrm{C}\right)\end{array}$ \\
\hline $\begin{array}{l}\text { Loctite } 9466 \text { (Brittle) } \\
\text { DP-460 (Ductile) }\end{array}$ & 33 & 8 & -55 to 120 \\
\hline
\end{tabular}
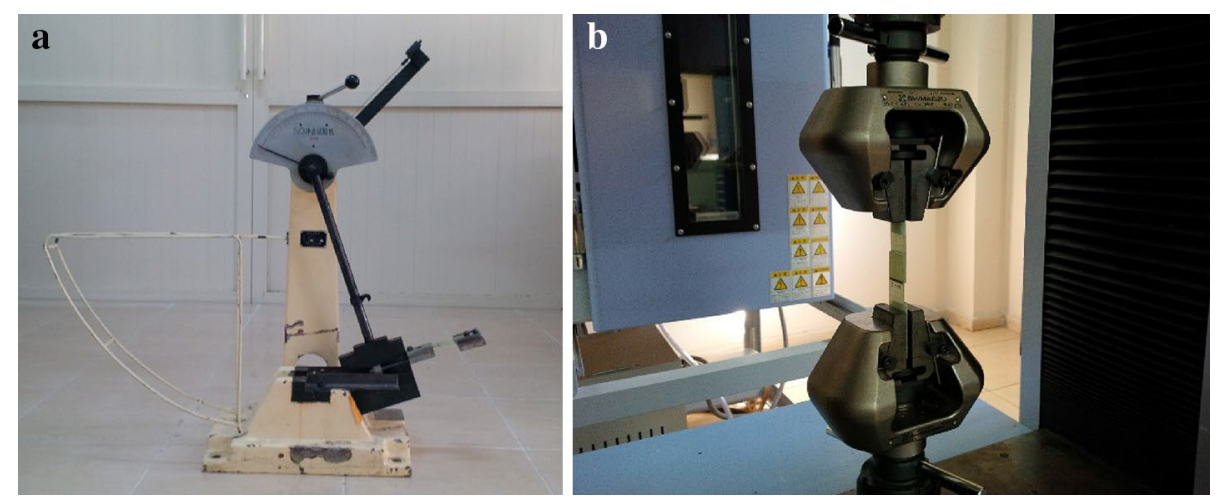

Fig. 2 a The experimental setup of impact test. b The experimental setup of tensile test

\section{Results and discussion}

The experimental results of impact loadings at the different energies were obtained using Charpy machine. The single impact was performed under 0 (zero), 5, 10, 15 and $20 \mathrm{~J}$ axial impact energies. The displacement diagrams of the adhesive of Loctite-9466 as a 
function of loadings of simple impact were shown in Fig. 3. As seen in Fig. 3, the failure strength force slightly decreased for the 10 and $15 \mathrm{~J}$ axial impacts, respectively. The experimental results showed us that the failure strength force increased slightly under $20 \mathrm{~J}$ impact loading.

Figure 4 shows the displacement diagrams of the adhesive of Loctite-9466 as a function of loadings of under repeated (three times). In that case, the value of the failure strength force for the energy of $10 \mathrm{~J}$ was obtained higher than those of the energies at 5 and $15 \mathrm{~J}$. However, we didn't get any result for the energy of $20 \mathrm{~J}$ under repeated axial impact loading in the charpy machine. Because of the higher energy and repeated loadings, the samples were failured.
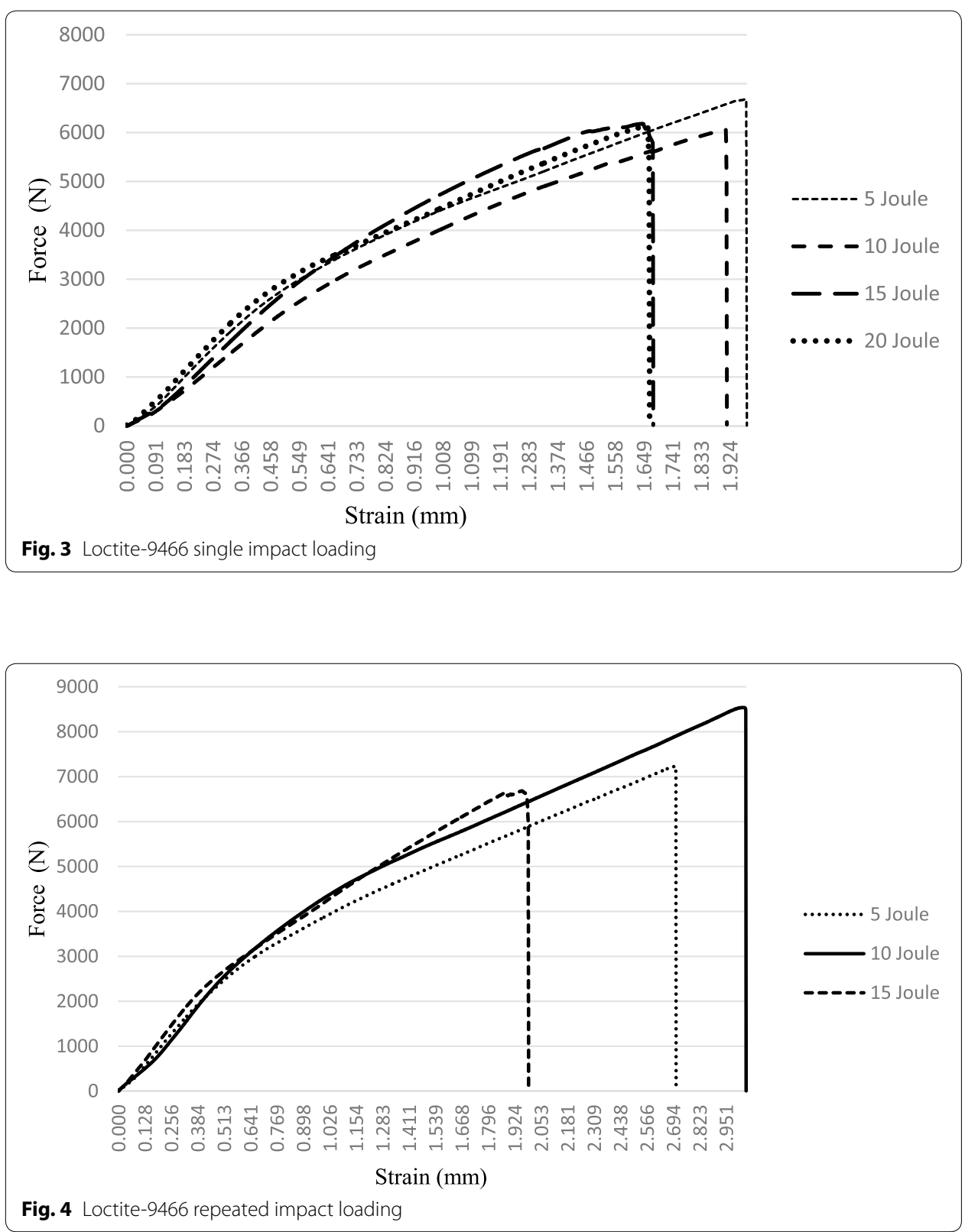
Furthermore, the same experiments were repeated for the ductile adhesive of DP-460. Figure 5 shows the displacement diagram of DP-460 under the single impact loading as a function of loadings. The single impact experiments were performed at the different energies of 5,10, 15 and $20 \mathrm{~J}$. According to experimental results, the failure strength was the highest for the energy of $10 \mathrm{~J}$. However, it has the smallest value under the energy of $20 \mathrm{~J}$ under axial impact loading because of the higher energy.

The displacement diagram for ductile adhesive of DP-460 under the repeated (three times) loadings at different impact energies of 5, 10, 15 and $20 \mathrm{~J}$ were shown in Fig. 6. The failure strength at the energy of $10 \mathrm{~J}$ was higher than those of the energies of 5 and $15 \mathrm{~J}$. However, the failure strength has the highest value when repeated axial impact force under $10 \mathrm{~J}$ because of the higher residual stress. Additionally, it reaches the maximum toughness value at $10 \mathrm{~J}$ axial impact loading.

The strength of joint under single impact energies for the Loctite-9466 and DP-460 is shown in Fig. 7. As seen in the figure, the strengths of the DP-460 are higher than those of Loctite-9466. It is also seen, the strengths for the energy of $10 \mathrm{~J}$ are higher than that of the energy of $5 \mathrm{~J}$. The strengths are nearly the same for $20 \mathrm{~J}$ energy. The strength of the DP-460 is higher than that of Loctite-9466 without an axial impact loading.

The strengths of the Loctite-9466 under repeated impact loadings at different energies are shown in Fig. 8. Repeated impact loadings were performed for three times. There is no tensile loading since the failure occured under $20 \mathrm{~J}$ repeated impact loadings. The ultimate forces for the impact energies of 5, 10 and $15 \mathrm{~J}$ are shown in Fig. 8. The maximum strength is seen at the energy of $10 \mathrm{~J}$ impact loading.

The comparison of experimental results of the Loctite-9466 adhesive applying both single and repeated impact energies are shown in Fig. 9. As seen in this figure, the repeated impact failure strengths are higher than those of the single impact results. The single impact failure strength can be obtained for $20 \mathrm{~J}$. However, the failure occurs for the repeated impacts under $20 \mathrm{~J}$ impact energy.

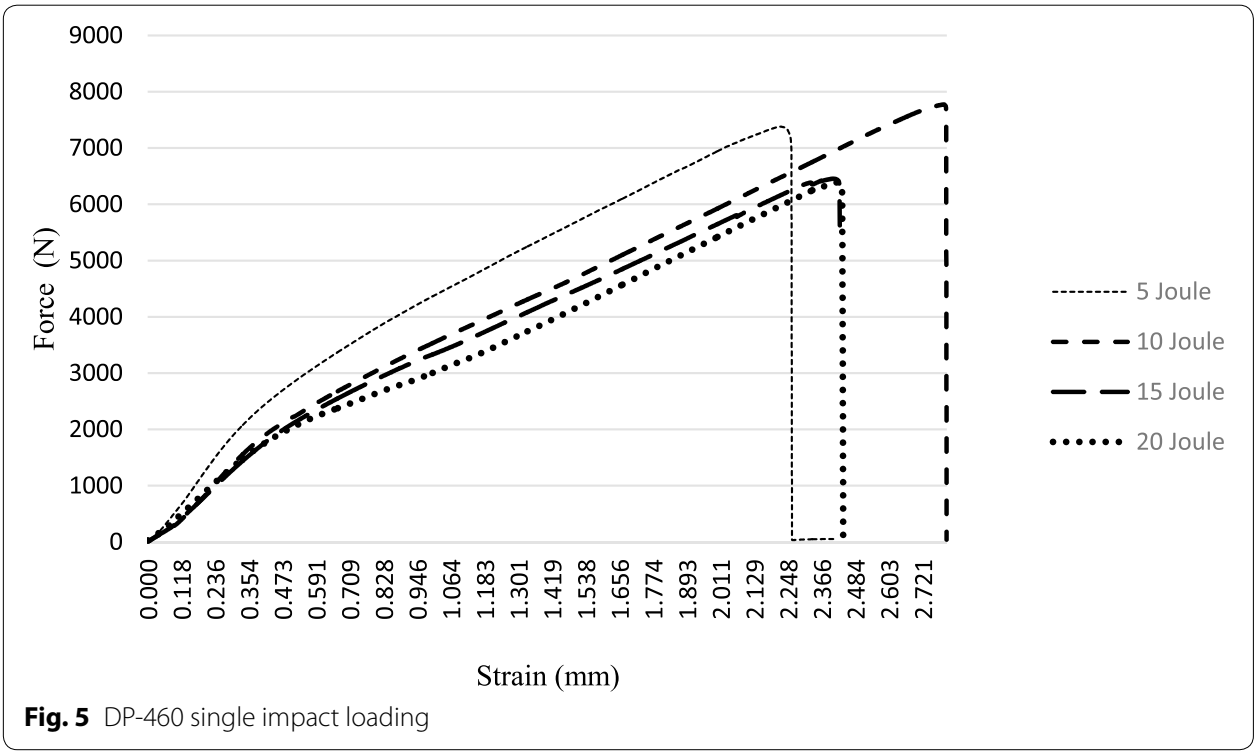



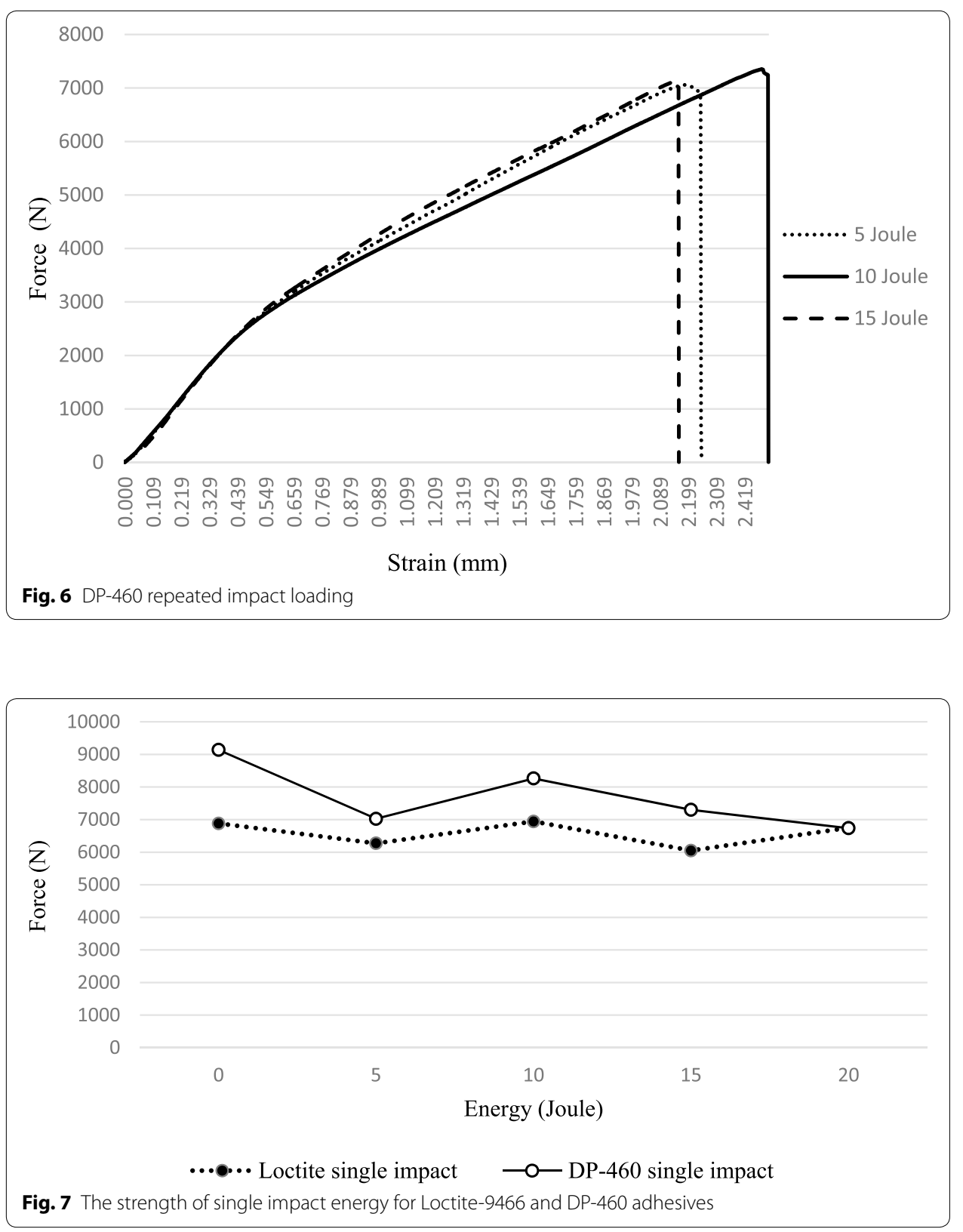

The single and repeated impact results for the DP-460 adhesive are shown in Fig. 10. The figure shows that the failure strengths for the single impacts are higher than that of repeated impacts. The failure occurs under $20 \mathrm{~J}$ impact for the repeated case during the axial impact loading.

The strengths of the joints for Loctite-9466 and DP-460 adhesives under repeated impacts (three times) are shown in Fig. 11. It is seen, the failure strength of the Loctite-9466 is higher than that of the DP-460 for 5 and 10 J. However, the failure strength of DP-460 is higher than that of Loctite-9466 for the 15 J energy. 

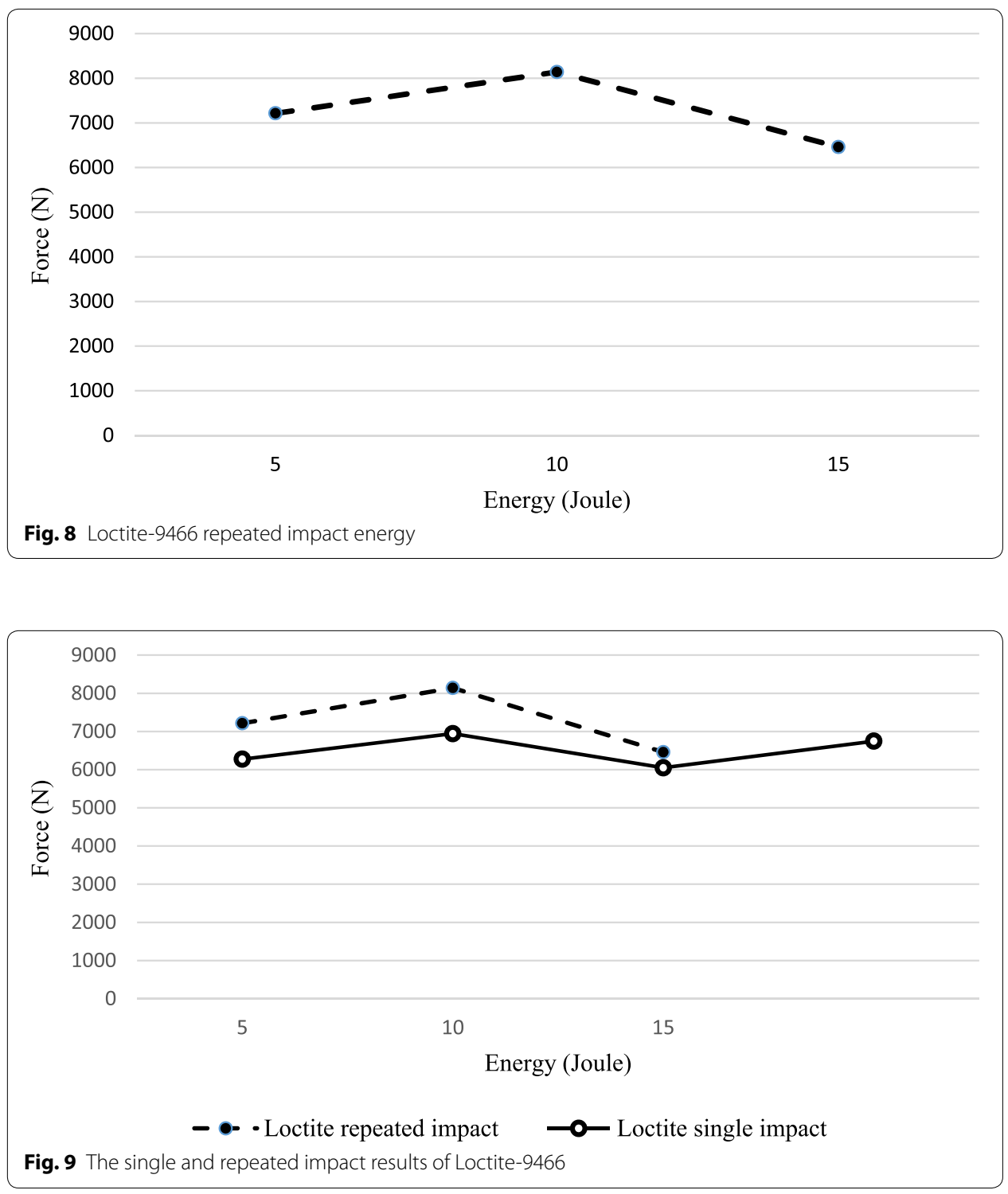

\section{Conclusion}

In this study, the failure impact strengths were found in the composite adherends joined by Loctite-9466 brittle adhesive and DP-460 ductile adhesive.

- The impact strengths were measured for the single and repeated (three times) axial loadings.

- The single and repeated loadings were performed under 5, 10, 15 and $20 \mathrm{~J}$. The strengths were obtained for 5, 10, 15 and $20 \mathrm{~J}$ for the single impact after measuring the tensile forces. But the failures occured under repeated $20 \mathrm{~J}$ loadings in all the joints without tensile loadings.

- The strengths of the DP-460 joints are higher than the Loctite-9466 joints for the single impacts. 

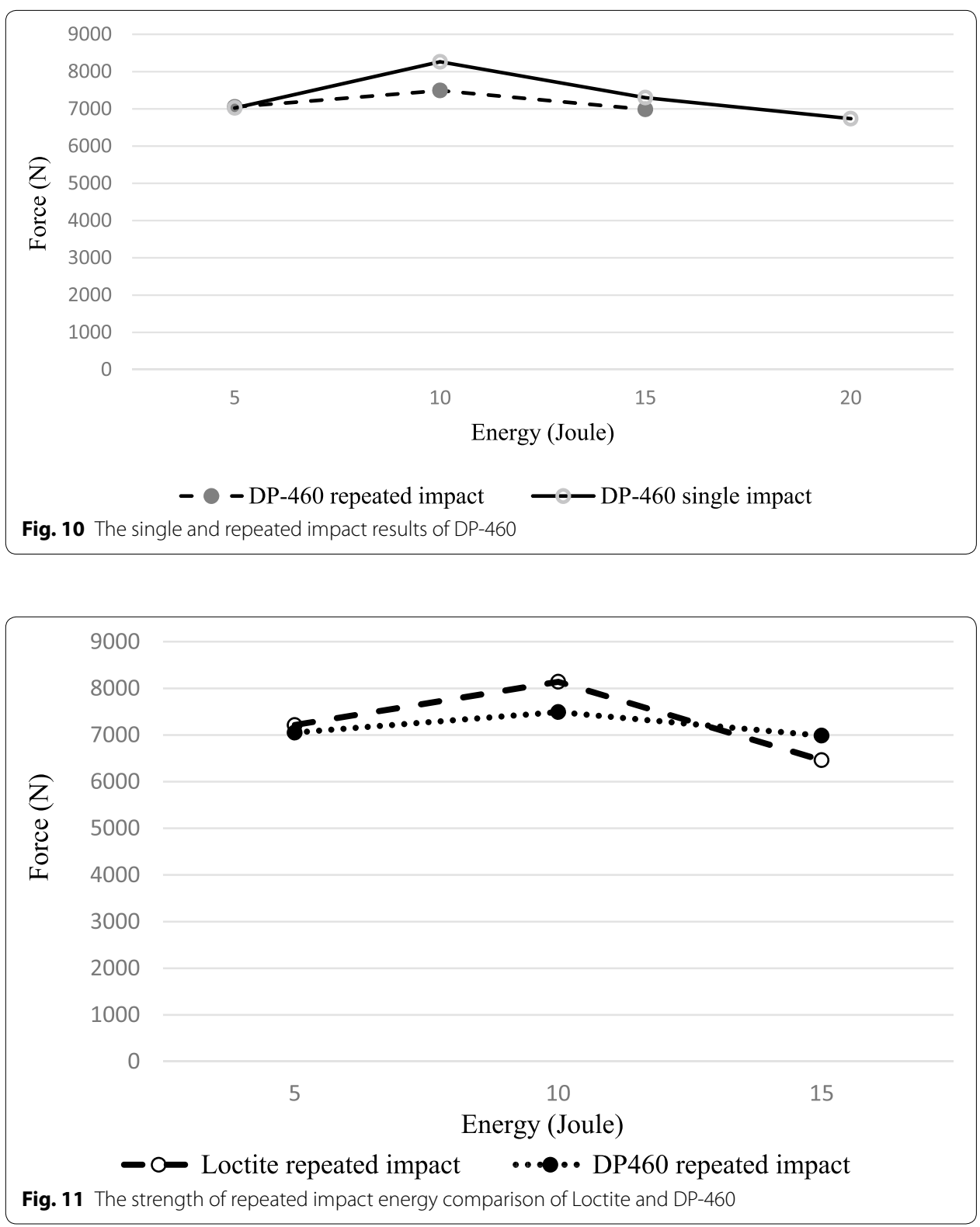

- The strengths of the Loctite-9466 are higher than those of the DP-460 in the 5 and 10 J for repeated impacts.

- The strength of the joints was found to be higher than that of other energy loadings fort he energy of $10 \mathrm{~J}$ impact loading for single and repeated cases.

- The failure strengths of Loctite-9466 under single impact was obtained smaller than that of repeated impact of Loctite-9466.

Authors' contributions

UK prepared the specimens and performed the experimental measurements and also helped to OS for writing the paper. OS and TB designed the experiments. OS and IFS made data analysis. TA and EA helped for UK and IFS. All authors read and approved the final manuscript. 


\section{Author details}

${ }^{1}$ Department of Mechanical Engineering, Faculty of Engineering and Architecture, Gediz University-lzmir, Menemen, Izmir, Turkey. ${ }^{2}$ Hasan Ferdi Turgutlu Technology Faculty, Celal Bayar University, Turgutlu, Manisa, Turkey. ${ }^{3}$ Faculty of Dentistry, Izmir Katip Celebi University, Cigli, Izmir, Turkey.

\section{Competing interests}

The authors declare that they have no competing interests.

Received: 11 August 2015 Accepted: 19 October 2015

Published online: 26 October 2015

\section{References}

1. Kihara K, Isono H, Yamabe H, Sugibayashi T. A study and evaluation of the shear strength of adhesively bonded single lap and T joints fort he automotive industry. Int J Adhes Adhes. 2003;23:253-9.

2. Vaidya UK, Gautam ARS, Hosur M, Dutta P. Experimental-numerical studies of transverse impact response of adhesively bonded lap joints in composite structures. Int J Adhes Adhes. 2006;26:184-98.

3. Yang CD, Huang H, Tomblin JS, Sun WJ. Elastic-plastic model of adhesive bonded single-lap composite joints. J Compos Mater. 2004;38:293-309.

4. Sayman O, Ozen M, Korkmaz B. Elasto-plastic stress distributions in adhesively bonded double lap joints. Mater Des. 2013:45:31-5.

5. Kim H, Kayir T, Mousseau SL. Mechanisms of damage formation in transversely impacted glass-epoxy bonded lap joints. J Compos Mater. 2005;39:2039-52.

6. Sayman O, Ozen M, Ozel A, Demir T, Korkmaz B. A non-linear elastic-plastic stress analysis in a ductile double-lap joint. Sci Eng Compos Mater. 2012;20(2):163-8.

7. Her SC. Stress analysis of adhesively-bonded lap joints. Compos Struct. 1999:47:673-8.

8. Keller T, Vallee T. Adhesively bonded lap joints from pultruded GFRP profiles. Part I: stress-strain analysis and failure modes. Compos B. 2005;36:331-40.

9. Avila AF, Bueno PDO. An experimental and numerical study on adhesive joints for composites. Compos Struct. 2001;64:531-7.

10. Aktas A, Polat Z. Improving strength performance of adhesively bonded single-lap composite joints. J Compos Mater. 2010;44:2919-28.

11. Sayman O, Arikan V, Dogan A, Soykok IF, Dogan T. Failure analysis of adhesively bonded composite joints under transverse impact and different temperatures. Compos B. 2013;54:409-14.

12. Bouchikhi AS, Megueni A, Gouasmi S, Boukoulda FB. Effect of mixed adhesive joints and tapered plate on stresses in retrofitted beams bonded with a fiber-reinforced polymer plate. Mater Des. 2013;50:893-904.

13. Goeij WC, Tooren MJL, Beukers A. Composite adhesive joints under cyclic loading. Mater Des. 1999;20:213-21.

14. http://www.loctite.co.uk/loctite-4087.htm?nodeid=8802629222401. Accessed 2 Feb 2015.

15. http://multimedia.3m.com/mws/media/661220/3mtm-scotch-weld-tm-epoxy-adhesive-dp460-ns-and-off-white. pdf. Accessed 2 Feb 2015.

\section{Submit your manuscript to a SpringerOpen ${ }^{\circ}$ journal and benefit from:}

- Convenient online submission

- Rigorous peer review

- Immediate publication on acceptance

- Open access: articles freely available online

- High visibility within the field

- Retaining the copyright to your article

Submit your next manuscript at $>$ springeropen.com 